\title{
PLANTAS DE COBERTURA DE SOLO COMO FONTE DE NITROGÊNIO AO MILHO(1)
}

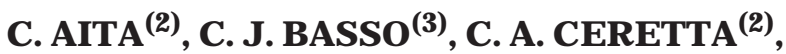 \\ C. N. GONÇALVES ${ }^{(4)} \&$ C. O. DA ROS(5)
}

\begin{abstract}
RESUMO
Durante o período de 1990/94, foi realizado um trabalho na área experimental do Departamento de Solos da Universidade Federal de Santa Maria (RS), num Argissolo Vermel ho distrófico arênico, para avaliar o potencial de al gumas plantas de cobertura de solo no fornecimento de $\mathrm{N}$ ao mi l ho no sistema plantio direto. $\mathrm{O}$ delineamento experimental foi o de blocos ao acaso, com parcelas subdivididas e quatro repetiçốes. Nas parcelas princi pais, foram utilizadas, em cada inverno, as leguminosas ervilhaca comum (Vicia sativa L.), ervilha forrageira (Pisum sativum var. arvense (L.) Poir), chícharo (Lathyrus sativus L.) e tremoço azul (Lupinus angustifol ius L.), a gramínea aveia preta (Avena strigosa Schieb.), além de um tratamento com pousio invernal (plantas invasoras). Nas subparcelas, foram aplicadas as doses de 0,80 e $160 \mathrm{~kg} \mathrm{ha}^{-1}$ de $\mathrm{N}$ no milho, na forma de uréia. Na média dos quatro anos, as duas espécies que produziram maior quantidade de matéria seca pela parte aérea foram o tremoço azul $\left(5.228 \mathrm{~kg} \mathrm{ha}^{-1}\right)$ e a aveia preta $\left(4.417 \mathrm{~kg} \mathrm{ha}^{-1}\right)$, seguidas do chícharo $\left(3.047 \mathrm{~kg} \mathrm{ha}^{-1}\right)$, ervilha forrageira (2.754 kg ha-1), ervilhaca comum (2.527 kg ha-1) e plantas invasoras do pousio invernal (1.197 $\left.\mathrm{kg} \mathrm{ha}^{-1}\right)$. Dentre as leguminosas, a espécie tremoço azul acumulou a maior quantidade de $\mathrm{N}$ na parte aérea $\left(113,7 \mathrm{~kg} \mathrm{ha}^{-1} \mathrm{de} \mathrm{N}\right)$. Os tratamentos que adicionaram menor quantidade de $\mathbf{N}$ ao solo pela fitomassa foram a aveia preta $\left(41,7 \mathrm{~kg} \mathrm{ha}^{-1} \mathrm{de} \mathrm{N}\right)$ e o pousio invernal $\left(20,5 \mathrm{~kg} \mathrm{ha}^{-1} \mathrm{de} \mathrm{N}\right)$. Aproximadamente, $60 \%$ do $\mathrm{N}$ acumulado na parte aérea das legumi nosas foi liberado durante os primeiros 30 dias após o seu manejo. Na ausência de adubação nitrogenada, o rendimento de grãos de milho foi maior após as legumi nosas do que após a aveia e o pousio invernal. As leguminosas diferiram entre si quanto ao potencial de fornecimento de $\mathbf{N}$ ao milho. Os maiores valores de equivalência em $\mathbf{N}$ mineral (EqN) foram obtidos com a ervilhaca (137 kg ha-1 de $\mathrm{N}$ ) e com o tremoço (122 kg ha-1 de N), evidenciando a possibilidade de redução das quantidades de $\mathbf{N}$ mineral por aplicar no mi l ho quando ele for cultivado em sucessão a estas duas legumi nosas.
\end{abstract}

Termos de indexação: leguminosas, plantio direto, adubação verde, decomposição.

\footnotetext{
(1) Recebido para publicação em janeiro de 2000 e aprovado em setembro de 2000.

(2) Professor do Departamento de Solos, Universidade Federal de Santa Maria - UFSM. CEP 97105-900 Santa Maria (RS).

(3) Doutorando do Programa de Pós-graduação em Agronomia, UFSM. E-mail: a9760358@alunop.ufsm.br

(4) Doutorando do Curso de Pós-graduação da Universidade Federal do Rio Grande do Sul - UFRGS. CEP $90001-970$ Porto Alegre (RS). E-mail: cristiano@hotmail.com.br

(5) Professor da Universidade de Cruz Alta - UNICRUZ. Caixa Postal 858, CEP 98025-810 Cruz Alta (RS).
} 


\title{
SUMMARY: COVER CROPS AS A SOURCE OF NITROGEN TO CORN
}

\begin{abstract}
A field experiment was carried out from 1990 to 1994 in the experimental area of the Soil Department at the Federal University of Santa Maria, State of Rio Grande do Sul, Brazil, on an Hapludalf to evaluate the potential of some winter legumes as $\mathrm{N}$ suppliers to no-tillage corn. A completely randomized block design with split-plots was used, with the winter crops in the main pl ots and the $\mathrm{N}$ rates for corn in thesplit-plots. In the main plots, the legumes common vetch (Vicia sativa L.), field pea (Pisum sativum var. arvense (L.) Poir), wild winter pea (Lathyrus sativus L.) and bluelupine(Lupinus angustifolius L.) and the graminea black oat (Avena strigosa Schieb.) were implanted every winter. A treatment with fallow was used as a reference. The rates of $\mathrm{N}$ for corn were 0,80 and $160 \mathrm{~kg} \mathrm{ha}^{-1}$, applied as urea. On average for the four years, the two specie that produced the greatest amounts of dry matter werebluelupine $\left(5,228 \mathrm{~kg} \mathrm{ha}^{-1}\right)$ and black oat $\left(4,417 \mathrm{~kg} \mathrm{ha}^{-1}\right)$, foll lowed by wild winter pea $\left(3,047 \mathrm{~kg} \mathrm{ha}^{-1}\right)$, field pea $\left(2,754 \mathrm{~kg} \mathrm{ha}^{-1}\right)$, common vetch $\left(2,527 \mathrm{~kg} \mathrm{ha}^{-1}\right)$, and winter fallow $\left(1,197 \mathrm{~kg} \mathrm{ha}^{-1}\right)$. Among the legumes, the blue lupine was the specie that accumulated thelargest amount of $\mathrm{N}$ in theaerial part (113.7 $\left.\mathrm{kg} \mathrm{ha}^{-1} \mathrm{of} \mathrm{N}\right)$. Thetreatments that added thesmallest amounts of $\mathrm{N}$ to the soil for the phytomass wereblack oat $\left(41.7 \mathrm{~kg} \mathrm{ha}^{-1}\right.$ of $\mathrm{N}$ ) and weeds under fallow conditions ( $20.5 \mathrm{~kg} \mathrm{ha}^{-1}$ of $\left.\mathrm{N}\right)$. A proximately, $60 \%$ of the $\mathrm{N}$ accumulated by theaboveground legume biomass was decomposed during thefirst 30 days after legumemanagement. When $\mathrm{N}$ fertilization was not used, corn grain yield was greatest after legumes than after oat or winter fallow. The legumes differed in their potential as $\mathrm{N}$ suppliers to corn. The largest values of equival ent mineral $\mathrm{N}$ were obtained with common vetch (137 kg ha-1 of $\mathrm{N}$ ) and blue lupine (122 kg ha-1 of $\mathrm{N}$ ), evidencing the possibility of reduction of theamounts of mineral $\mathrm{N}$ to beapplied to corn when cultivated in succession to thesetwo legumes.
\end{abstract}

Index terms: legumes, no-tillage, green manure, decomposition.

\section{INTRODUÇÃO}

No Rio Grande do Sul, a maior parte da área cultivada com espécies comerciais no verão permanece em pousio durante o inverno. Nesse período do ano, ocorrem as maiores precipitações pluviométricas, resultando em perdas expressivas de sol o e de nutrientes por erosão, já que a cobertura do solo proporcionada pelas plantas invasoras durante o inverno é normalmente deficiente. 0 nitrogênio é o nutriente mais afetado nesse processo, provocando sérias limitações na produtividade das culturas. Isto porque a principal fonte desse nutriente é a matéria orgânica que se encontra na camada superficial do sol oe sofre uma perda seletiva durante a erosão hídrica (Da Ros, 1993).

Uma das alternativas mais promissoras para enfrentar essa situação consiste na utilização de plantas de cobertura de solo durante o inverno. Dentre as espécies avaliadas, as leguminosas têm recebido atenção especial, pois, além de propiciarem cobertura do solo, apresentam potencial de fixação do $\mathrm{N}_{2}$ atmosférico em simbi ose com R hizobium. Com a decomposição de seus resíduos, o N orgânico será mineralizado e absorvido pela cultura em sucessão, reduzindo, assim, as quantidades de $\mathrm{N}$ mineral por utilizar nas culturas comerciais de verão (Muzilli, 1978; Derpsch et al., 1985; Heinzmann, 1985;
Pavinato et al., 1994; Da Ros \& Aita, 1996). Para o milho, isto é relevante, uma vez que a fertilização nitrogenada é um componente importante do custo de produção da cultura.

Uma das maneiras de avaliar o potencial das leguminosas em fornecer $\mathrm{N}$ às culturas comerciais é pela determinação da equivalência em $\mathrm{N}$ mineral (EqN) das leguminosas (Smith et al., 1987). E mbora tal característica seja fundamental à seleção daquelas leguminosas de inverno mais promissoras como fonte de $\mathrm{N}$ ao milho, poucos estudos têm sido realizados nesta área no Brasil, especialmente no sistema plantio direto.

Este trabal ho foi desenvolvido com o objetivo de avaliar o desempenho de plantas de cobertura de sol os de inverno num Argissolo Vermel ho distrófico arênico da Depressão Central do Rio Grande doSul, bem como sua capacidade em fornecer nitrogênio para o milho em plantio direto.

\section{MATERIAL E MÉTODOS}

O experimento foi realizado, durante quatro anos agrícolas (1990/91 a 1993/94), em área experimental do Departamento de Sol os da U niversidadeF ederal de Santa Maria, região fisiográfica da Depressão 
Central doRioGrandedoSul, numArgissoloVermelho distrófico arênico (Hapludalf) (EMBRAPA, 1999), com textura superficial franco-arenosa. Na camada de $0-20 \mathrm{~cm}$, o solo apresentou as seguintes características iniciais: $590 \mathrm{~g} \mathrm{~kg}^{-1}$ de areia, 210 de silte, 150 de argila; $\mathrm{pH}$ em água $=5,5$; índice SMP $=$

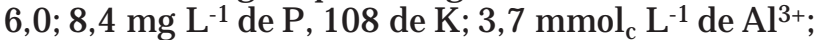
3,2 de $\mathrm{Ca}^{2+}+\mathrm{Mg}^{2+} \mathrm{e} 7,5 \mathrm{~g} \mathrm{~kg}^{-1}$ deMO. A declividade média da área experimental é de $5 \%$.

A precipitação pluviométrica mensal para o período de 1990 a 1994 é mostrada no quadro 1.

Anteriormente à instalação do experimento, a área foi cultivada com as seqüências aveia preta/ soja (1988/89) e ervilhaca comum + aveia preta/ milho (1989/90), com aplicação de fertilizantes minerais nas culturas de verão. Por ocasião da instalação do experimento (1990/91), o solo foi preparado pelo sistema convencional (aração e gradagem), com incorporação de $3,0 \mathrm{Mg} \mathrm{ha}^{-1}$ de cal cário dol omítico. A partir de 1990, as espécies de inverno foram sempre semeadas a Ianço, sem adubação mineral, e as sementes incorporadas ao solo por meio de grade niveladora com pequeno ângulo de corte para a cobertura das sementes, com mínima mobilização do solo. As sementes das leguminosas foram inoculadas com rizóbio específico.

Utilizou-se o delineamento experimental de blocos ao acaso, com parcelas subdivididas e quatro repetições. Nas parcelas principais ( $15 \times 5 \mathrm{~m})$, utilizaram-se cinco plantas de cobertura de inverno: ervilhaca comum (Vicia sativa L.), ervil ha forrageira (Pisum sativum var. arvense (L.) Poir), chícharo (Lathyrus sativus L.), tremoço azul (Lupinus angustifolius L.) e aveia preta (Avena strigosa

\section{Quadro 1. Precipitação pluviométrica ocorrida nos anos agrícolas de condução do experimento e precipitação normal (média dos últimos trinta anos) $)^{(1)}$}

\begin{tabular}{lrrrrrr}
\hline \multicolumn{1}{c}{ Mês } & Normal & $\mathbf{1 9 9 0}$ & $\mathbf{1 9 9 1}$ & $\mathbf{1 9 9 2}$ & $\mathbf{1 9 9 3}$ & $\mathbf{1 9 9 4}$ \\
\hline & & \multicolumn{7}{c}{ mm } \\
\cline { 2 - 7 } & & & & & \\
J aneiro & 144 & 109 & 48 & 82 & 366 & 47 \\
Fevereiro & 140 & 164 & 36 & 253 & 87 & 256 \\
Março & 129 & 188 & 100 & 134 & 109 & 111 \\
A bril & 157 & 253 & 330 & 271 & 66 & 192 \\
Maio & 191 & 123 & 54 & 157 & 237 & 283 \\
J unho & 163 & 86 & 178 & 142 & 168 & 177 \\
J ulho & 135 & 92 & 131 & 127 & 227 & 294 \\
Agosto & 145 & 19 & 57 & 83 & 13 & 154 \\
Setembro & 163 & 226 & 59 & 152 & 98 & 130 \\
Outubro & 152 & 163 & 47 & 134 & 192 & 224 \\
N ovembro & 121 & 278 & 25 & 77 & 253 & 138 \\
Dezembro & 129 & 117 & 322 & 67 & 204 & 120
\end{tabular}

(1) Informações obtidas na Estação Meteorológica da Universidade Federal de Santa Maria.
Schieb.), além de um tratamento com pousio invernal (plantas invasoras). Nas subparcelas $(5 \times 5 \mathrm{~m})$, foram aplicadas três doses de nitrogênio $\left(0,80\right.$ e $\left.160 \mathrm{~kg} \mathrm{ha}^{-1}\right)$ na cultura do milho, na forma de uréia.

As plantas de cobertura foram manejadas na fase de florescimento pleno, com uma grade niveladora com pequeno ângulo de corte, visando à interrupção do ciclo vegetativo e o acamamento dessas plantas. No tratamento com pousio invernal, o manejo da vegetação espontânea foi efetuado com o uso de herbicida à base de glyphosate (1,92 kg ha-1 de i.a.).

Considerando que as condições edafoclimáticas exercem grande influência sobre o desempenho das culturas, optou-se por fazer uma análise conjunta dos resultados de quatro anos (1990 a 1994) das variáveis matéria seca e nitrogênio acumulado nas plantas de cobertura de solo de inverno. Por esse motivo, foram considerados os dados destas variáveis dos anos de 1990 e 1991, que foram apresentados em Da Ros \& Aita (1996).

Em cada ano agrícola, a semeadura do milho (Cargill 511 A) foi efetuada diretamente sobre os resíduos culturais das plantas de cobertura de inverno, aproximadamente 20 dias após o manejo das plantas por meio de semeadora equipada com mecanismo sulcador tipo facão para a distribuição do adubo e duplo disco defasado para as sementes. O período de 20 dias entre o manejo das espécies ea semeadura do milho foi estabelecido na tentativa de se evitarem os problemas rel acionados com a ação de produtos com efeito al el opático para o milho, liberados na fase inicial de decomposição das culturas de cobertura, conforme constataram Guenzi \& McCalla (1962). O espaçamento utilizado foi de um metro entrelinhas com sete sementes por metro linear. A pós o desbaste, foram dei xadas cinco plantas por metro linear, perfazendo uma população final de 50.000 plantas ha-1.

A partir da análise do sol o do experimento, foram aplicados, anualmente, em todos os tratamentos, $45 \mathrm{~kg} \mathrm{ha}^{-1}$ de $\mathrm{P}_{2} \mathrm{O}_{5}$ e 53 de $\mathrm{K}_{2} \mathrm{O}$ nas formas de superfosfato triplo e cloreto de potássio, respectivamente. A quantidade de N (na forma de uréia) aplicada por ocasião da semeadura do milho foi de $15 \mathrm{~kg} \mathrm{ha}^{-1}$ nos tratamentos com 80 e 160 de $\mathrm{N}$ e o restante em cobertura, em duas parcelas iguais, aproximadamente aos 45 e 70 dias da semeadura.

Por ocasião do florescimento pleno das espécies de cobertura, foi avaliada a sua produção de fitomassa, coletando-se, al eatoriamente, uma área de $0,8 \mathrm{~m}^{2}$ por parcela. A matéria seca foi determinada após a secagem em estufa a $65^{\circ} \mathrm{C}$, até massa constante. No tecido vegetal, seco e moído, determinaram-se a concentração de $\mathrm{N}$ por digestão úmida e a destilação por meio de destilador de arraste de vapor semimicro-K jel dahl (Tedesco et al., 1985). O teor de carbono orgânico do tecido vegetal foi analisado pel o método Walkley \& Black, descrito por Tedesco et al. (1985), em uma única amostra de 
tecido vegetal de cada espécie. Essa amostra composta foi constituída por quatro subamostras, cuja massa foi proporcional à produção de matéria seca em cada uma das quatro repetições.

Nos dois primeiros anos do experimento (1990 e 1991), avaliou-se a liberação de nitrogênio dos resíduos culturais após o manejo das plantas de cobertura, pela coleta de uma área de $0,8 \mathrm{~m}^{2}$ entre as linhas de milho, nas subparcelas que não receberam nitrogênio mineral. No campo, as amostras foram pesadas, subamostrando-se, aproximadamente, 1/3 do material, tendo sido o restante devol vido ao respectivolocal deamostragem. Nas subamostras, secas em estufa a $65^{\circ} \mathrm{C}$ até peso constantee moídas, analisou-se oteor deN, conforme descrito anteriormente para o tecido vegetal das plantas de cobertura.

As col etas de resíduos culturais foram realizadas até 180 dias após o manejo das espécies, tendo sido, em 1990, o intervalo entre col etas de 30 dias e, em 1991, de 10 dias, no primeiro mês, e de 30 dias, atéo final do período. Cada col eta foi realizada em uma área distinta dentro das subparcelas amostradas. Para estimar a liberação de $\mathrm{N}$ dos resíduos culturais, consi deraram-se as quantidades remanescentes de $\mathrm{N}$ (matéria seca $x$ concentração em $\mathrm{N}$ ) em cada amostragem ao longo do período de avaliação.

O rendimento de grãos de milho foi avaliado em uma área de $16 \mathrm{~m}^{2}$, coletando-se as quatro linhas centrais, desprezando-se 0,5 m nas extremidades de cada subparcela. Os valores foram ajustados para $13 \%$ de umidade.

A estimativa da equivalência em $\mathrm{N}$ mineral ( $\mathrm{EqN})$ das leguminosas baseou-se em Smith et al. (1987), os quais definiram a EqN como sendo a quantidade de N mineral por aplicar na cultura comercial, após pousio, para se obter rendimento equivalente ao tratamento com leguminosa, sem aplicação de N. Por exemplo, um valor de $\mathrm{EqN}$ de $70 \mathrm{~kg} \mathrm{ha}^{-1}$ de $\mathrm{N}$ de uma leguminosa significa ser necessária a aplicação de $70 \mathrm{~kg} \mathrm{ha}^{-1}$ de $\mathrm{N}$ no milho após pousio para atingir uma produção de grãos equivalente àquela obtida com o uso exclusivo da leguminosa (sem o uso de $\mathrm{N}$ mineral).

Para a análise estatística das características avaliadas, calculou-se a média dos valores obtidos nos quatro anos de experimentação, considerando cada ano uma repetição. As médias provenientes da variável de natureza qualitativa (plantas de cobertura) foram submeti das à análise de variância eas médias comparadas pel o teste de Duncan a $5 \%$. $\mathrm{O}$ efeito das doses de $\mathrm{N}$ sobre o rendimento de grãos de milho foi avaliado pela análise de regressão. Como foram consideradas somente três doses de $\mathrm{N}$ no milho, utilizou-se o modelo linear, ajustado pelas médias das observações dos quatro anos. As curvas relativas à liberação de $\mathrm{N}$ dos resíduos culturais foram ajustadas aos val ores observados por meio de model os lineares.

\section{RESULTADOS E DISCUSSÃO}

\section{Rendimento de matéria seca e acúmulo de $\mathbf{N}$ pelas plantas de cobertura}

Pode-se observar que, na média dos quatro anos, tanto o rendimento de matéria seca como a quantidade de nitrogênio acumulado no tecido vegetal da parte aérea diferiram entre as espécies avaliadas (Quadro 2). As duas espécies que produziram a maior quantidade de matéria seca foram o tremoço azul $\left(5.228 \mathrm{~kg} \mathrm{ha}^{-1}\right)$ e a aveia preta (4.417 kg ha-1), seguidas do chícharo, ervilha forrageira e ervilhaca comum, que não diferiram entre si. O tratamento em que o solo permaneceu em pousio durante oinvernofoi aquel equecontribuiu com a menor quantidade de fitomassa.

Em experimento realizado no planal to do Rio Grande do Sul em um Brunizém Avermel hado com $3,2 \%$ de matéria orgânica (MO) e $25 \%$ de argila, Pavinato et al. (1994) encontraram produções de matéria seca para aveia preta, ervilha forrageira, ervilhaca comum e chícharo de 5.710, 4.950, 2.960 e $2.920 \mathrm{~kg} \mathrm{ha}^{-1}$, respectivamente. J á Cal egari (1987), trabalhando com estas mesmas espécies e mais o tremoço azul em um Latossol o do estado do Paraná, encontrou produções de 4.150, 5.490, 3.322, 3.924 e $4.429 \mathrm{~kg} \mathrm{ha}^{-1}$, para aveia preta, ervilha forrageira, ervilhaca comum, chícharo e tremoço azul, respectivamente.

No presente experimento (Quadro 2), a ervilhaca comum e, principalmente, a ervil ha forrageira foram as espécies que apresentaram menor produção de matéria seca em relação às obtidas por Pavinato et al. (1994) e Calegari (1987). É provável que tais espécies sejam mais exigentes em fertilidade de solo

Quadro 2. Produção de matéria seca, nitrogênio acumulado e relação $\mathrm{C} / \mathrm{N}$ das plantas de cobertura de solo que antecederam o milho, nos anos agrícolas de 1990/91 a 1993/94

\begin{tabular}{llcc}
\hline $\begin{array}{c}\text { Planta de cobertura } \\
\text { no inverno }\end{array}$ & $\begin{array}{c}\text { Matéria } \\
\text { seca }\end{array}$ & $\begin{array}{c}\text { Nitrogênio } \\
\text { acumulado }\end{array}$ & $\begin{array}{c}\text { Relação } \\
\text { C/N }\end{array}$ \\
\cline { 2 - 3 } & \multicolumn{2}{c}{$\mathrm{kg} \mathrm{ha}^{-1}-$} & \\
E rvilhaca comum & $2.527 \mathrm{bc}^{(1)}$ & $76,7 \mathrm{~b}$ & $10,5(2)$ \\
E rvilha forrageira & $2.754 \mathrm{~b}$ & $69,2 \mathrm{~b}$ & 13,1 \\
Chícharo & $3.047 \mathrm{~b}$ & $83,5 \mathrm{~b}$ & 12,4 \\
Tremoço azul & $5.228 \mathrm{a}$ & $113,7 \mathrm{a}$ & 15,4 \\
Aveia preta & $4.417 \mathrm{a}$ & $41,7 \mathrm{c}$ & 34,9 \\
Pousio & $1.197 \mathrm{C}$ & $20,5 \mathrm{c}$ & 17,6 \\
\hline
\end{tabular}

(1) Médias seguidas de mesma letra, na coluna (média dos quatro anos) não diferem entre si (Duncan a $5 \%$ ). (2) Não foi feita a análise estatística da relação $\mathrm{C} / \mathrm{N}$ porque o teor de $\mathrm{C}$ foi avaliado a partir de uma mostra composta, constituída pelas quatro repetições. 
do que as demais, razão por que produziram mais fitomassa no L atossol o e no Brunizém Avermel hado do quenoArgissoloVermel ho distrófico arênico deste trabal ho que apresentava um teor inicial de MO no sol o de apenas $0,75 \%$. Tais resultados mostram queo uso de plantas de cobertura de sol o durante o inverno deve ser precedido da avaliação do seu desempenho nas condições edafoclimáticas em que se pretende utilizá-las.

Pode-se observar que o tremoço azul foi a leguminosa que acumulou a maior quantidade de nitrogênio na parteaérea (113,7 kg ha-1) (Quadro 2). A análise estatística indicou que não houve diferença para a quantidade de $\mathrm{N}$ acumulado pelas leguminosas chícharo, ervilhaca comum e ervilha forrageira. O fato de o tremoço ter acumulado aproximadamente $50 \%$ mais nitrogênio do que a média das outras três leguminosas deve estar relacionado com sua maior produção de fitomassa, que foi $88 \%$ superior à das demais leguminosas.

No caso das leguminosas, é importante destacar que boa parte do $\mathrm{N}$ incorporado ao tecido vegetal foi obtida via fixação simbiótica do $\mathrm{N}_{2}$ atmosférico. A proporção do $\mathrm{N}$ acumulado queéfixado biologicamente varia de acordo com a disponibilidade de $\mathrm{N}$ mineral no solo, com a eficiência fixadora de $\mathrm{N}$ por parte das estirpes de bactérias introduzi das via inoculação das sementese, ou, coma população de bactérias presentes originalmente no solo (Aita, 1997). A melhoria do balanço de $\mathrm{N}$ no solo por meio da introdução de leguminosa é particularmente importante em sol os pobres em matéria orgânica como o do presente experimento, onde a disponibilidade de $\mathrm{N}$ constitui fator limitante à produção daqueles cereais mais exigentes em $\mathrm{N}$, como o milho.

A aveia preta foi a espécie que apresentou a segunda maior produção de matéria seca entre as plantas de cobertura, embora a quantidade de $\mathrm{N}$ acumulado tenha sido apenas a metade daquela encontrada na média das quatro leguminosas. Tais resultados confirmam os relatados por Aita et al. (1994), quetrabalharam no mesmo tipo de sol o deste estudo, e mostraram a importância do cultivo das leguminosas de inverno quando o objetivo for o de aumentar o aporte de $\mathrm{N}$ ao solo. Todavia, a aveia pode ser uma alternativa interessante para aquelas situações em que a necessidade maior seja a adição ao sol o de fitomassa e carbono. Além disso, o fato de a aveia ter acumulado $104 \%$ mais $\mathrm{N}$ do que as plantas invasoras do pousio invernal (Quadro 2) demonstra que esta espécie pode contribuir também para a diminuiç̧ão das perdas de $\mathrm{N}$ por lixiviação de nitrato no perfil do solo duranteo inverno, mantendo o nutriente no tecido vegetal.

\section{Liberação de $\mathbf{N}$ dos resíduos culturais}

A liberação de $\mathrm{N}$ dos resíduos culturais, nos dois anos de experimentação, foi mais rápida na fase inicial da decomposição (Figura 1). Considerando a média das quatro leguminosas, $57 \%$ do N presente inicialmente na fitomassa foi liberado nos primeiros 30 dias após o manejo em 1990/91 (Figura 1a) e 60\% em 1991/92 (Figura 1b). Aos 120 dias, esses valores aumentaram para $80 \%$, no primeiro ano, e $85 \%$, no segundo. Na média dos dois anos, a quantidade de $\mathrm{N}$ liberado da pal ha da aveia foi de $38 \%$, aos 30 dias, e de $54 \%$, aos 120 dias, caracterizando a menor taxa de liberação de $\mathrm{N}$ da gramínea em relação às leguminosas.

Observa-se que a liberação de $\mathrm{N}$ dos resíduos culturais nos primeiros 30 dias após o manejo foi diretamente relacionada com a quantidade de $\mathrm{N}$ acumulado pelas espécies na fase de florescimento pleno (Figura 2).

O fato de o $\mathrm{N}$ das leguminosas avaliadas ser rapidamenteliberado após o seu manejo poderá ter conseqüências importantes do ponto de vista de fornecimento de $\mathrm{N}$ à cultura em sucessão, já que o $\mathrm{N}$ liberado poderá ser perdido no solo principalmente por lixiviação de nitrato, se ocorrerem chuvas intensas enão houver uma cultura capaz de absorver oN liberado. Assim, para maximizar oaproveitamento deste $\mathrm{N}$, deve-se efetuar o plantio da cultura comercial logo após o manejo das leguminosas de inverno, conforme recomenda Heinzmann (1985), ou deve-se promover a sel eção de plantas de cobertura cuja taxa de mineralização do $\mathrm{N}$ dos resíduos culturais ocorra com maior sincronia possível em relação à demanda de $\mathrm{N}$ da cultura em sucessão.

\section{Rendimento de grãos de milho}

O efeito das plantas de cobertura sobre o rendimento de grãos em cada dose de $\mathrm{N}$ é mostrado no quadro 3. Os dados obtidos indicam a interação significativa a $5 \%$ de plantas de cobertura e doses de N. Observa-se que, na ausência de adubação nitrogenada, o rendimento médio de grãos de mi lho em sucessão às leguminosas foi superior em 89 e $43 \%$ nos tratamentos com aveia preta e pousio invernal, respectivamente. Os aumentos proporcionados pelas leguminosas são da mesma magnitude daqueles encontrados por Aita et al. (1994) e por Pavinato et al. (1994), ao trabalharem com estas mesmas espécies, e por Frye et al. (1985), ao compararem o rendimento do milho após ervilhaca peluda (Vicia villosa) ao obtido após centeio, em experimento realizado durantecinco anos no sistema plantio direto. Tais resultados mostram que a utilização de leguminosas no inverno constitui uma fonte alternativa de $\mathrm{N}$ para o milho cultivado em sucessão.

O comportamento diferenciado entreleguminosas e gramíneas no fornecimento de $\mathrm{N}$ ao milho pode ser explicado pela capacidade das primei ras em fixar o $\mathrm{N}_{2}$ atmosférico e pelas diferenças na relação $\mathrm{C} / \mathrm{N}$ e na composição bioquímica dessas espécies, que são as principais características inerentes ao tecido vegetal com reflexos diretos sobre a sua velocidade 


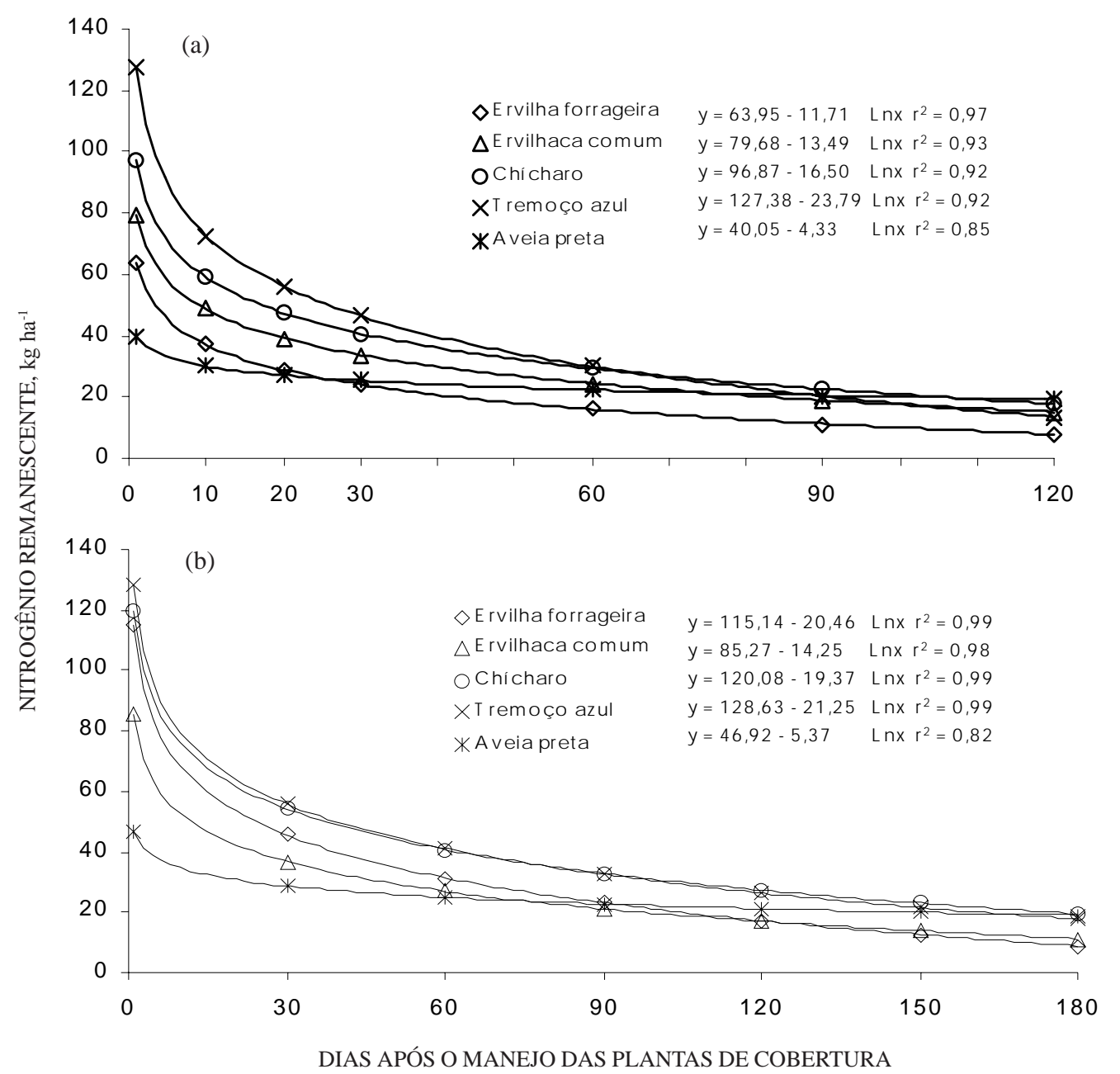

Figura 1. Quantidade de nitrogênio liberado pelos resíduos das espécies de inverno no ano agrícola 1990/91 (a) e 1991/92 (b).

Quadro 3. Rendimento de grãos de mi lho cultivado em sucessão a plantas para cobertura de solo no inverno, em três níveis de adubação nitrogenada mi neral. Médias dos anos agrícolas 1990/91 a 1993/94

\begin{tabular}{|c|c|c|c|}
\hline \multirow{2}{*}{$\begin{array}{l}\text { Planta de } \\
\text { cobertura } \\
\text { no inverno }\end{array}$} & \multicolumn{3}{|c|}{ Dose de nitrogênio no milho (kg ha-1) } \\
\hline & 0 & 80 & 160 \\
\hline & \multicolumn{3}{|c|}{$-\mathrm{kg} \mathrm{ha}^{-1}$} \\
\hline Ervilhaca comum & $4.548 \mathrm{a}^{(1)}$ & $4.900 \mathrm{ab}$ & $5.089 a$ \\
\hline Ervilha forrageira & $3.635 a b$ & $4.569 \mathrm{abc}$ & $4.832 \mathrm{a}$ \\
\hline Chícharo & $3.969 \mathrm{a}$ & $4.564 \mathrm{abc}$ & $4.675 \mathrm{a}$ \\
\hline Tremoço azul & $4.379 a$ & $5.014 \mathrm{a}$ & $4.991 \mathrm{a}$ \\
\hline Aveia preta & $2.188 \mathrm{C}$ & $4.047 \mathrm{c}$ & $4.500 \mathrm{a}$ \\
\hline Pousio(2) & $2.887 \mathrm{bc}$ & $4.172 \mathrm{bc}$ & $4.667 \mathrm{a}$ \\
\hline
\end{tabular}

de decomposição e, conseqüentemente, sobre a disponibilidade de $\mathrm{N}$ no solo (Recous et al., 1995). Observa-se, no quadro 3, que a relação $\mathrm{C} / \mathrm{N}$ média das leguminosas é de 12,8, enquanto na aveia ela é de 34,9 , valor superior àquele considerado como sendo de equilíbrio entre os processos microbianos de imobilização e mineralização de $\mathrm{N}$ que é de aproximadamente 25 (Paul \& Clark, 1989).

Para utilizar o carbono da palha de aveia na biossíntesee como fonte de energia, os microrganismos imobilizam $\mathrm{N}$ mineral do solo, diminuindo a sua disponibilidade para o milho. Isto fica evidenciado nos resultados do quadro 2 , onde, na ausência de adubação nitrogenada mineral, o rendimento de grãos após a aveia foi inferior em 32\% em relação ao do pousio invernal.

Analisando a resposta do milho à adubação nitrogenada mineral, em sucessão às plantas de cobertura, observa-se que, com a aplicação de $160 \mathrm{~kg} \mathrm{ha}^{-1}$ de $\mathrm{N}$, o rendimento de grãos foi 
semel hanteentre as diferentes espécies de cobertura (Quadro 3). Como foram usadas apenas três doses de $\mathrm{N}$, utilizou-se a regressão linear para ajustar o rendimento de grãos de milho de acordo com a adubação nitrogenada após cada cultura de cobertura (Figura 3).

\section{Equivalência em $\mathbf{N}$ mineral (EqN) das leguminosas}

Para estimar a equivalência em $\mathrm{N}$ mineral das leguminosas, utilizou-se a equação de regressão entre doses de $\mathrm{N}$ e rendimento de grãos para 0 sistema pousio/milho (F igura 3) $(Y=3.019+11,13 \mathrm{X})$.
SubstituindoY pelos rendimentos de grãos de milho obtidos em sucessão aos tratamentos com leguminosas, na ausência de adubação nitrogenada mineral $\left(3.635,3.969,4.379\right.$ e $4.548 \mathrm{~kg} \mathrm{ha}^{-1}$, para ervilha forrageira, chícharo, tremoço e ervilhaca, respectivamente), é possível estimar $X$, que representa a EqN de cada leguminosa. Os valores de EqN encontrados foram de 55, 85, 122 e $137 \mathrm{~kg} \mathrm{ha}^{-1}$ de N, para ervilha forrageira, chícharo, tremoço azul e ervilhaca comum, respectivamente. Com exceção da ervilha forrageira, estes valores são próximos daqueles encontrados por Mitchell \& Tell (1977), para ervilhaca peluda e trevo encarnado, e por

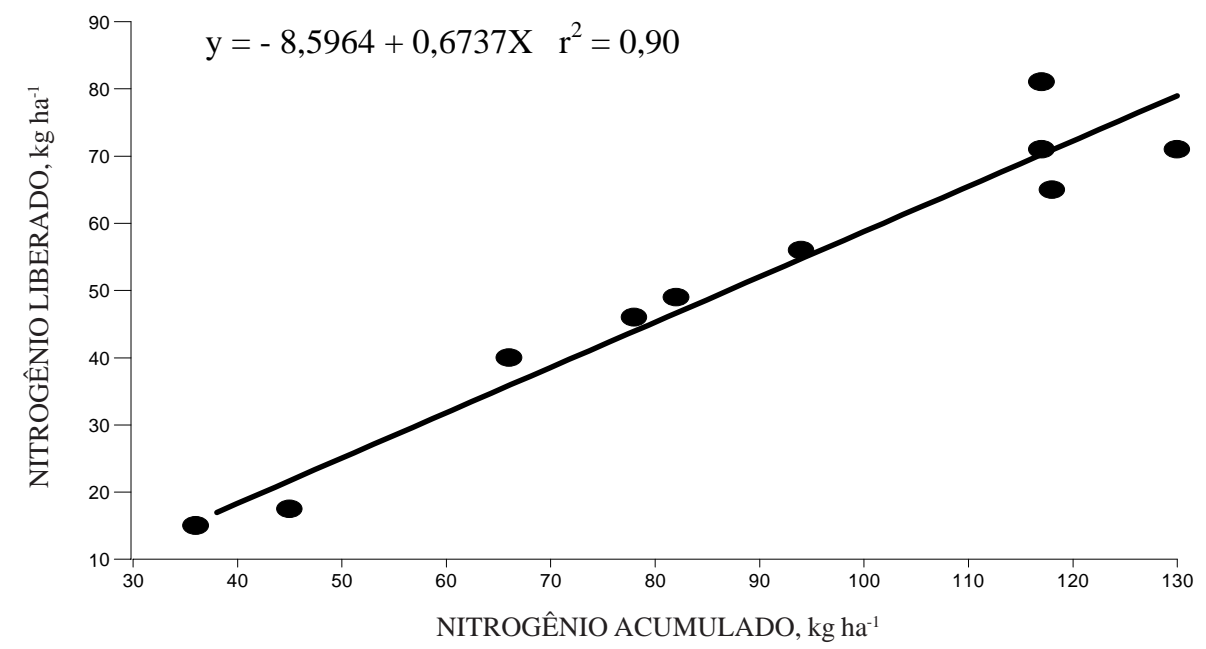

Figura 2. Relação entre o $\mathbf{N}$ acumulado na fitomassa das espécies de inverno na fase de florescimento pleno e o N liberado até 30 dias após o manejo nos anos agrícolas 1990/91 e 1991/92.

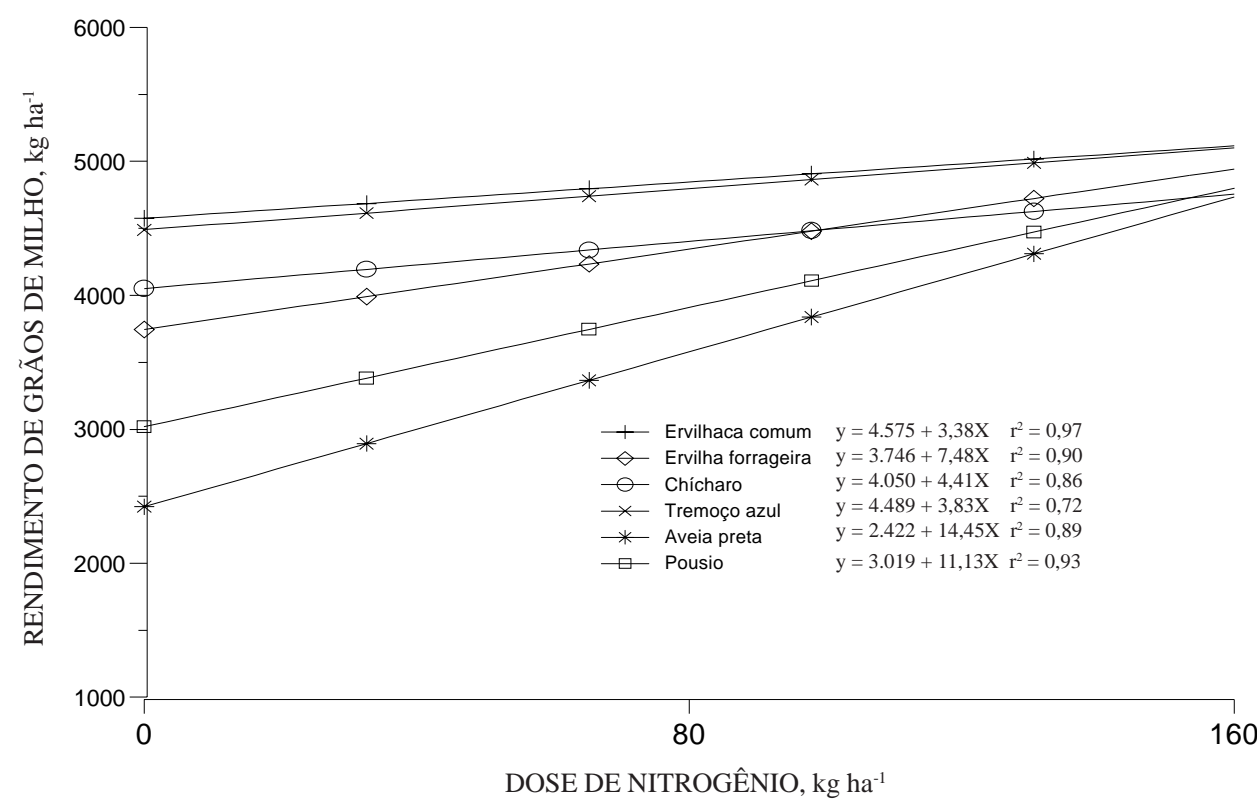

Figura 3. Relação entre dose de nitrogênio e rendimento de grãos de milho cultivado em sucessão a plantas de cobertura de solo. 
Bruulsema \& Christie (1987), para alfafa e trevo vermelho. Nesses trabalhos, o fornecimento de $\mathrm{N}$ pelas leguminosas foi equivalente a uma aplicação de $90-125 \mathrm{~kg} \mathrm{ha}^{-1}$ de $\mathrm{N}$ mineral.

Trabal hando em um Latossol o do Paraná, Muzilli (1978) verificou que o mil ho em sucessão à ervilhaca comum produziu o equivalente à dose de $80 \mathrm{~kg} \mathrm{ha}^{-1}$ de $\mathrm{N}$ mineral no tratamento em pousio invernal, val or este inferior à $\mathrm{EqN}$ desta mesma espécie neste trabalho.

O fato de a ervilhaca comum ter apresentado maior EqN, embora tenham sido adicionadas pela parte aérea quantidades de $\mathrm{N}$ inferiores às do tremoço azul e próximas às do chícharo e ervilha forrageira (Quadro 2), deve estar relacionado com a liberação diferenciada de $\mathrm{N}$ dos resíduos culturais das plantas durante a sua decomposição no solo. $\mathrm{Na}$ figura 1, observa-seque, na média dos dois primeiros anos, as quantidades de $\mathrm{N}$ liberado nos primeiros 30 dias após o manejo do tremoço e da ervilhaca foram de aproximadamente $71 \mathrm{~kg} \mathrm{ha}^{-1}$ de N (57\%) e $43 \mathrm{~kg} \mathrm{ha}^{-1}$ de N (53\%), respectivamente. É provável que a quantidade de $\mathrm{N}$ liberado pelo tremoço nesse período tenha excedido a capacidade de assimilação deN pelomilhonos estádios iniciais dedesenvol vimento desta cultura.

Acredita-sequeas diferenças na taxa de liberação de nutrientes dos resíduos culturais de plantas de cobertura de solo, relatadas por Heinzmann (1985) e Oliveira (1994), sejam devidas às características intrínsecas de cada espécie, as quais condicionam sua velocidade de decomposição pela população microbiana do solo, como, por exemplo, a relação $\mathrm{C} / \mathrm{N}$, a proporção entre tal os efol has e a composição bioquímica do tecido vegetal (De-Polli \& Chada, 1989).

Para que o aproveitamento do $\mathrm{N}$ das plantas de cobertura seja maximizado pelo milho, é fundamental que a liberação de $\mathrm{N}$ dos resíduos culturais ocorra em sincronia com a demanda de $\mathrm{N}$ do milho (Stute \& Posner, 1995). A ervilhaca foi a espécie que mel hor atendeu a este pré-requisito, em oposição à ervilha forrageira. Estudos que relacionem características das plantas de cobertura eliberação de $\mathrm{N}$ devem ser intensificados, já que as informações de pesquisa nesta área são escassas. Elas são fundamentais para a mel hor compreensão da dinâmica do $\mathrm{N}$ no solo durante a decomposição das plantas de cobertura e, portanto, para a recomendação dessas plantas como fonte de $\mathrm{N}$ ao milho.

Os resultados obtidos em quatro anos de experimentação no campo indicam que a capacidade de fornecimento de $\mathrm{N}$ ao milho pelas leguminosas de inverno diferiu entre as espécies. A demanda de $\mathrm{N}$ do milho foi parcialmente atendida, como no caso do chícharo e da ervilha forrageira, e, totalmente, quando a cultura foi estabelecida em sucessão ao tremoço azul eà ervil haca comum. Todavia, deve-se considerar que a magnitude de substituição da adubação nitrogenada mineral do milho pelas leguminosas de inverno depende de diversos fatores, dentre os quais se podem destacar a quantidade de $\mathrm{N}$ acumulado pelas leguminosas, a velocidade com que o nutriente é li berado dos resíduos culturais, a disponibilidade de $\mathrm{N}$ do solo, o potencial de rendimento do milho e o nível tecnológico empregado na cultura.

\section{CONCLUSÕES}

1. Com exceção da ervilhaca comum, a produção de fitomassa das plantas de cobertura de solo foi significativamente maior do que aquela da vegetação espontânea que se desenvolveu no pousio invernal.

2. Aproximadamente, $60 \%$ do $\mathrm{N}$ acumulado na parteaérea das leguminosas foi liberado dos resíduos culturais durante os primeiros 30 dias após o manejo das espécies.

3. O N acumulado na parte aérea das espécies foi maior nas leguminosas do que na aveia e na vegetação espontânea, destacando-se o tremoço com os maiores val ores.

4. Não houve resposta à adubação nitrogenada do milho, quando cultivado em sucessão à ervilhaca comum e tremoço azul.

5. A equivalência em $\mathrm{N}$ mineral para ervilhaca, tremoço, chícharo e ervilha forrageira, em relação ao pousio invernal, foi de, respectivamente, 137, 122, 85 e $55 \mathrm{~kg} \mathrm{ha}^{-1}$ de $\mathrm{N}$.

\section{LITE RATURA CITADA}

AITA, C.; CERETTA, C.A.; THOMAS, A.L.; PAVINATO, A. \& BAYER, C. Espécies de inverno como fonte de nitrogênio para o milho no sistema de cultivo mínimo e feijão em plantio direto. R. Bras. Ci. Solo, 18:101-108, 1994.

AITA, C. Dinâmica do nitrogênio no solo durante a decomposição de plantas de cobertura: efeito sobre a disponibilidade de nitrogênio para a cultura em sucessão. In: FRIES, M.R. \& DALMOLIN , R.S.D., eds. Atualização em recomendação de adubação e calagem: ênfase em plantio direto. Santa Maria, Pallotti, 1997. p.76-111.

BRUULSEMA, T.W. \& CHRISTIE, B.R. Nitrogen contribution to succeeding corn from alfafa and red clover. Agron. J ., 79:96100, 1987.

CALEGARI, A. Adubação verde erotação de culturas no sudoeste do Paraná. In: REUNIÃO DE ROTAÇÃO DE CULTURAS, Ponta Grossa, 1987. Anais. Ponta Grossa, 1987. p.1-16.

DA ROS, C.O. Plantas de inverno para cobertura do solo e fornecimento de nitrogênio ao milho em plantio direto. Santa Maria, Universidade Federal de Santa Maria, 1993. 85p. (Tese de Mestrado) 
DA ROS, C.O. \& AITA, C. Efeito de espécies de inverno na cobertura do solo e fornecimento de nitrogênio ao milho em plantio direto. R. Bras. Ci. Solo, 20:135-140, 1996.

DE-POLLI, H. \& CHADA, S.S. Adubação verde incorporada ou em cobertura na produção de milho em solo de baixo potencial de produtividade. Pesq. Agropec. Bras., 13:287293, 1989.

DERPSCH, R.; SIDIRAS, N. \& HEINZNANN, F.X. Manejo do sol o com coberturas verdes de inverno. Pesq. Agropec. Bras., 20:761-773, 1985.

EMPRESA BRASILEIRA DE PESQUISA AGROPECUÁRIA EMBRAPA. Centro Nacional de Pesquisa de Solos. Sistema Brasileiro de Classificação de Solos. Brasília, 1999. 412p.

FRYE, W.W.; SMITH, W.G. \& WILLIAMS, R.J . Economics of winter cover crops as a source of nitrogen for no-till corn. J . Soil Water Conser., 40:246-249, 1985.

GUENZI, W.D. \& MCCALLA, T.M. Inhibition of germination and seedling devel opment by crop residues. Soil Sci. Soc. Proc., 26:456-458, 1962.

HEINZMANN, F.X. Resíduos culturais de inverno e assimilação de nitrogênio por culturas de inverno. Pesq. Agropec. Bras., 20:1021-1030, 1985

MITCHELL, W.H. \& TEEL, M.R. Winter-annual cover crops for no-tillage corn production. Agron. J ., 69:569-573, 1977.
MUZILLI, O. O manejo da fertilidade do solo: a prática da adubação verde. In: FUNDAÇÃO INSTITUTO AGRONÔMICO DO PARANÁ, Manual agropecuário para o Paraná. Londrina, 1978. p.57-58.

OLIVEIRA, E.L. Coberturas verdes de inverno e adubação nitrogenada em algodoeiro. Pesq. Agropec. Bras., 18:235241, 1994.

PAVINATO, A.; AITA, C.; CERETTA, C.A. \& BEVILAQUA. G.P. Resíduos culturais de espécies de inverno e o rendimento de grãos de milho no sistema de cultivo mínimo. Pesq. Agropec. Bras., 29:427-432, 1994.

PAUL, E.A. \& CLARK, F.E. Soil microbiology and biochemistry. San Diego, Academic Press, 1989. 273p.

RECOUS, S.; ROBIN, D.; DARWIS, D. \& MARY, B. Soil inorganic $\mathrm{N}$ availability: effect on maize residue decomposition. Soil Biol. Biochem., 27:1529-1538, 1995.

SMITH, M.S.; FRYE, W.W. \& VARCO, J .J . Legume winter cover crops. In: STEWART, B.A., ed. Advances in soil science. New York, Springer-Verlag, 1987. p.95-139.

STUTE, J.K. \& POSNER, J.L. Synchrony between legume nitrogen release and corn demand in the Upper Midwest. Agro. J ., 87:1063-1069, 1995.

TEDESCO, M.J.; VOLKWEISS, S.J . \& BOHNEN, H. Análise de solo, plantas e outros materiais. Porto Alegre, Universidade Federal do Rio Grande do Sul, 1985. 188p. (Boletim Técnico de Solos, 5) 
C. AITA et al.

R. Bras. Ci. Solo, 25:157-165, 2001 